\title{
Intraoperative regional myocardial acidosis and reduction in long-term survival after cardiac surgery
}

\author{
Shukri F. Khuri, $M D^{a, b, c}$ \\ Nancy A. Healey, BS ${ }^{a}$ \\ Monir Hossain, MS \\ Vladimir Birjiniuk, MD ${ }^{\mathrm{a}, \mathrm{b}, \mathrm{c}}$ \\ Michael D. Crittenden, MD ${ }^{a, b, c}$ \\ Miguel Josa, $\mathrm{MD}^{\mathrm{a}}$ \\ Patrick R. Treanor, CCPa \\ Samer F. Najjar, MD ${ }^{\mathrm{a}}$ \\ Dharam J. Kumbhani, MBBS, MD \\ William G. Henderson, $\mathrm{PhD}^{\mathrm{e}}$
}

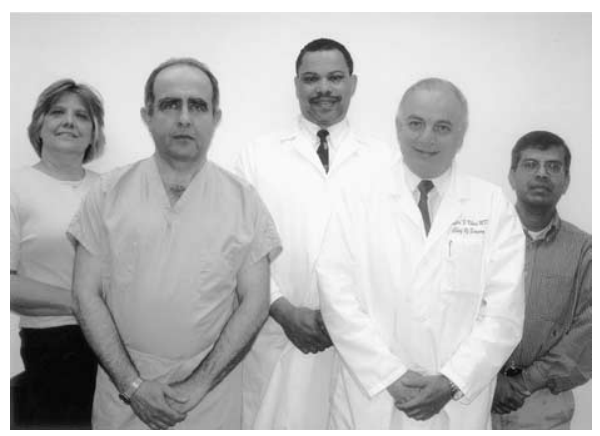

From the Surgical Service, VA Boston Healthcare System, Boston, Mass, ${ }^{\mathrm{a}}$ Harvard Medical School, Boston, Mass, ${ }^{\mathrm{b}}$ Brigham and Women's Hospital, Boston, Mass, ${ }^{c}$ Massachusetts Veterans Epidemiology Research and Information Center, Boston, Mass, ${ }^{\mathrm{d}}$ and Colorado Health Outcomes Group, Denver, Colo. ${ }^{\mathrm{e}}$

Supported by research funds from the Department of Veterans Affairs and the Richard Warren Surgical Research and Educational Fund, Westwood, Mass.

Received for publication Feb 11, 2004; revisions received March 22, 2004; accepted for publication May 20, 2004

Address for reprints: Shukri F. Khuri, MD, Chief, Surgical Service (112), VA Boston Healthcare System, 1400 VFW Pkwy, West Roxbury, MA 02132 (E-mail: shukri.khuri@ med.va.gov).

J Thorac Cardiovasc Surg 2005;129:372-81

$0022-5223 / \$ 30.00$

Copyright (c) 2005 by The American Association for Thoracic Surgery

doi:10.1016/j.jtcvs.2004.05.020
Background: Regional myocardial acidosis, as measured with tissue $\mathrm{pH}$ electrodes during cardiac surgery, has been shown to be reflective of regional myocardial ischemia. This study examined the relationship between intraoperative regional myocardial acidosis and long-term survival of patients undergoing cardiac surgery with cardiopulmonary bypass.

Methods: A total of 496 adult patients who underwent valve replacement, coronary artery revascularization, or both with intraoperative myocardial $\mathrm{pH}$ monitoring in the anterior and posterior left ventricular walls were followed up for 3 to 17 years (average $10.2 \pm 4.9$ years) for all cause mortality. Regional myocardial acidosis in each patient was defined by the lower of the anterior and posterior wall $\mathrm{pH}$ values.

Results: A bivariate automatic interaction detection analysis identified three significant regional myocardial acidosis thresholds that affected long-term mortality: $\mathrm{pH}_{37 \mathrm{C}}$ less than 6.63 before aortic crossclamping, integrated mean $\mathrm{pH}_{37 \mathrm{C}}$ less than 6.34 during the period of aortic crossclamping, and $\mathrm{pH}_{37 \mathrm{C}}$ less than 6.73 at discontinuation of cardiopulmonary bypass. Cox proportional hazard regression analysis identified each of these thresholds to be independently determinant of survival, with $\mathrm{pH}_{37 \mathrm{C}}$ during aortic crossclamping having the highest risk ratio (risk ratio $2.15,95 \%$ confidence interval 1.37-3.37). Raising $\mathrm{pH}_{37 \mathrm{C}}$ from lower than threshold before aortic crossclamping to higher than threshold during clamping increased the median survival by $40.2 \%$.

Conclusion: In adult patients undergoing cardiac surgery with cardiopulmonary bypass, regional myocardial ischemic acidosis before aortic crossclamping, during aortic crossclamping, and at discontinuation of cardiopulmonary bypass are independently associated with reduced long-term postoperative survival. Reversing or avoiding myocardial acidosis during cardiac surgery improves long-term patient survival.

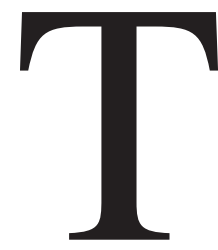

he quest for an intraoperative on-line metabolic marker of regional myocardial tissue ischemia has been the subject of basic and clinical translational research in our laboratory since $1972 .{ }^{1}$ During the first phase of this research (1972-1979), a rise in myocardial tissue $\mathrm{PCO}_{2}$, measured with mass spectrometry, and a fall in myocardial tissue $\mathrm{pH}$, measured with a newly developed electrode, were validated in a series of large animal experiments as quantitative measures of the extent of regional 
myocardial ischemia and decreased coronary perfusion. The $\mathrm{pH}$-sensing methodology was further developed during the subsequent phases of this research and was brought to the operating room in 1982, enabling for the first time the continuous monitoring of regional myocardial $\mathrm{pH}$ throughout the entire intraoperative course of a cardiac surgical operation. ${ }^{2}$ Early in the intraoperative monitoring experience, wide variations in myocardial $\mathrm{pH}$ between the anterior and posterior left ventricular walls were observed, underscoring a need for routine monitoring of myocardial $\mathrm{pH}$ in both walls simultaneously. The first 8 years of clinical myocardial $\mathrm{pH}$ monitoring at our center were mostly observational, aiming primarily to characterize the time course and clinical correlates of regional myocardial $\mathrm{pH}$ changes and validating in patients the role of myocardial tissue acidosis as a quantitative measure of regional myocardial ischemia and lack of regional delivery of the cardioplegic solution. ${ }^{2-11}$ Considering that normal myocardial $\mathrm{pH}$ is 7.2, regional myocardial acidosis was observed in varying degrees and with varied frequencies throughout the course of cardiopulmonary bypass (CPB). ${ }^{1}$ Before the period of aortic crossclamping $(A C)$, when the $\mathrm{pH}$ electrodes were first placed in the heart, regional myocardial acidosis was observed mostly in patients with severe coronary artery disease or left ventricular hypertrophy, particularly in those with unstable angina and a hibernating myocardium. During the period of $A C$, progressive regional ischemia was invariably observed in myocardial segments that were not reached by the cardioplegic solution. Myocardial acidosis in these segments reflected the lack of washout of locally accumulated hydrogen ions. ${ }^{1,12}$ The regional distribution of the cardioplegic solution during this period, as assessed by the degree of washout of the hydrogen ion, was highly unpredictable from one patient to another, despite the application of standardized cardioplegia delivery protocols. ${ }^{1}$ Patients who exhibited regional acidosis before AC were also more likely to have regional acidosis develop during AC. Acidosis during AC correlated with clinical evidence of inadequate myocardial protection. ${ }^{2,7,11}$ After release of the AC, during the period of reflow, persistent acidosis was more likely to be observed in patients who had sustained severe regional acidosis during $\mathrm{AC}$ and in patients who had inadequate coronary revascularization. Inadequate revascularization was assessed by the failure of myocardial $\mathrm{pH}$ to rise after establishing flow through newly constructed grafts. ${ }^{13}$ Hearts that did not have acidosis during $\mathrm{AC}$ and did not show evidence of inadequate revascularization were most likely to defibrillate spontaneously after $\mathrm{AC}$ and to be weaned from CPB without inotropic support, irrespective of the duration of AC. ${ }^{1}$

After the initial observational phase of intraoperative myocardial $\mathrm{pH}$ monitoring, $\mathrm{pH}$-guided myocardial management techniques were gradually developed at our institu- tion, mostly aimed at reducing intraoperative regional myocardial acidosis and ensuring effective and homogeneous delivery of the cardioplegic solution during AC. ${ }^{1}$ This study was conducted to elucidate further the clinical significance of intraoperative myocardial acidosis/ischemia and its reversal in the course of cardiac surgery by relating the myocardial $\mathrm{pH}$ changes before $\mathrm{AC}$, during $\mathrm{AC}$, and at end of reperfusion to the long-term survival of 496 patients who were followed up for an average of 10 years after undergoing cardiac surgery with intraoperative myocardial $\mathrm{pH}$ monitoring.

\section{Materials and Methods}

Between 1982 and 1997, a total of 535 cardiac surgery patients underwent intraoperative on-line monitoring of myocardial tissue $\mathrm{pH}$ in the anterior and posterior walls of the left ventricle. Institutional review board approval was obtained and patient consent forms were used before obtaining Food and Drug Administration approval for this technology in 1987. Because of limited availability of the electrodes, they were used selectively, mostly in highrisk patients who were anticipated to undergo relatively prolonged periods of AC and in patients who consented to enroll in specific studies in which myocardial $\mathrm{pH}$ was a study end point.

\section{Intraoperative Measurement of Myocardial pH}

The details of the monitoring methodology have been previously published elsewhere. ${ }^{3}$ After institution of $\mathrm{CPB}$, two right-angled glass electrodes ( $1 \mathrm{~mm}$ in diameter and $10 \mathrm{~mm}$ in depth) were inserted perpendicularly, one into the anterior left ventricular wall and one into the posterior, midway between the base and the apex. The electrodes were placed in the same topographic area in each patient, irrespective of the nature of the patient's coronary artery disease if present. Myocardial temperature was measured with a thermistor, which was incorporated into the mid shaft of the $\mathrm{pH}$ electrode after 1993. A record of myocardial $\mathrm{pH}$ and temperature, sampled every 20 seconds, was generated for each electrode. Three $\mathrm{pH}$ values, corrected to $37^{\circ} \mathrm{C}\left(\mathrm{pH}_{37 \mathrm{C}}\right)$, were abstracted from this record (Figure 1): (1) $\mathrm{pH}_{37 \mathrm{C}}$ just before $\mathrm{AC}$, (2) the integrated mean $\mathrm{pH}_{37 \mathrm{C}}$ during $\mathrm{AC}$, and (3) the last $\mathrm{pH}_{37 \mathrm{C}}$ value recorded before removal of the electrode, usually within minutes after the discontinuation of CPB. For each time point in each patient, the lower $\mathrm{pH}_{37 \mathrm{C}}$ value recorded from either the anterior or the posterior electrode defined the magnitude of regional myocardial acidosis encountered in that patient.

\section{Methods of Myocardial Protection}

All patients underwent a single period of AC and left ventricular venting, mostly through the right superior pulmonary vein. Saphenous vein grafts were constructed before valve replacement and were used as conduits for cardioplegia delivery. Saphenous vein graft proximal anastomoses were performed during partial aortic occlusion after release of the AC and defibrillation. Hypothermic crystalloid cardioplegia was replaced with hypothermic blood cardioplegia in 1991. Myocardial temperature during AC averaged around $15^{\circ} \mathrm{C}$ during the first half of the study period and around $23^{\circ} \mathrm{C}$ during the second half. In valve operations, cardioplegia was administered through the aortic root and the orifice of the main 


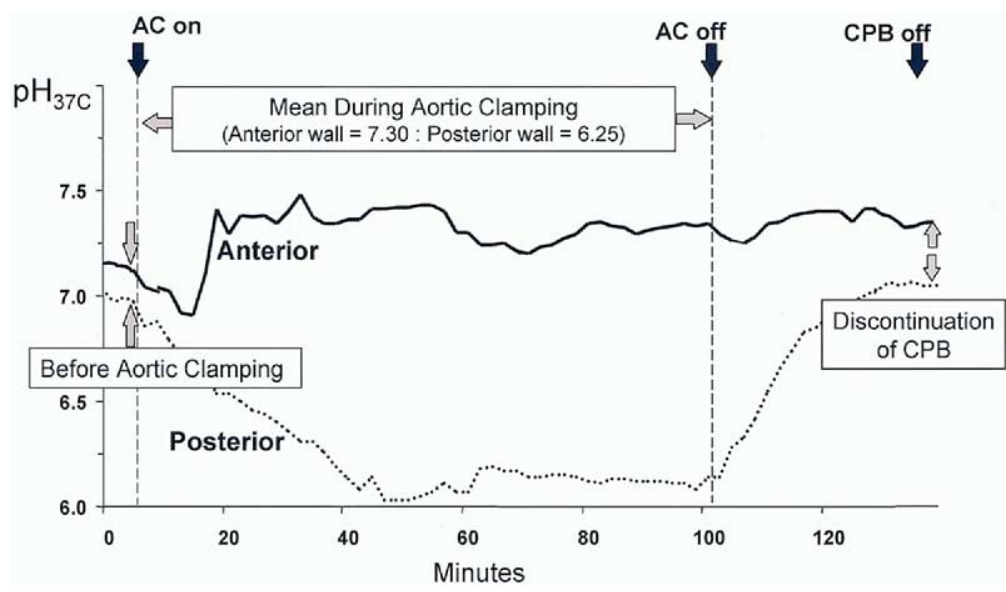

Figure 1. Intraoperative myocardial $\mathrm{pH}_{37 \mathrm{c}}$ recorded from electrodes placed in anterior (solid line) and posterior (dotted line) walls of left ventricle of 65 -year-old man undergoing aortic valve replacement. Time points at which cumulative myocardial $\mathrm{pH}_{37 \mathrm{c}}$ data were obtained for this study are illustrated on figure. Integrated mean $\mathrm{pH}_{37 \mathrm{C}}$ values during AC were 7.30 in anterior wall and 6.25 in posterior wall. In this study, lower of anterior and posterior $\mathrm{pH}_{37 \mathrm{c}}$ values in each patient defined degree of regional acidosis; in this patient it was posterior wall $\mathrm{pH}$ for each time point.

coronary arteries (if the aortic root was opened), and since 1991 through the coronary sinus as well. In coronary artery bypass grafting (and saphenous vein grafting accompanying valve replacement), cardioplegia was administered through the aortic root and through the proximal ends of newly constructed grafts. Before development of our $\mathrm{pH}$-guided myocardial management techniques, cardioplegia was administered continuously as much as possible and stopped only when the operative field needed to be clear. $^{7}$

The initial period of myocardial $\mathrm{pH}$ monitoring in the study patients (1982-1990) was purely observational, and no attempts were made to alter myocardial management techniques on the basis of myocardial $\mathrm{pH}$ readings. Subsequently, as the clinical significance of intraoperative myocardial acidosis became more apparent, we started exploring and developing $\mathrm{pH}$-guided myocardial management methods and techniques that would direct the cardioplegic solution to acidotic segments and prevent or reverse regional acidosis. By the end of 1997, we could elucidate a series of intraoperative interventions with which severe regional myocardial acidosis could be prevented in most patients, and the specific sites of cardioplegia delivery, the temperature of the cardioplegic solution, and the rate of delivery of the cardioplegic solution were all determined primarily by the myocardial $\mathrm{pH}$ response and varied widely from patient to patient. ${ }^{1}$

\section{Assessment of Long-term Survival}

The patients were initially tracked through the electronic patient records of the Veterans Affairs (VA) Boston Healthcare System and 9 additional referring VA medical centers in New England, as well as the research records of clinical studies in which many of the patients had been enrolled. This left 55 patients unaccounted for, 50 of whom were listed as dead by the VA Beneficiary Identification and Record Locator System (BIRLS), which has been shown to be $95 \%$ accurate in depicting the vital status of US veterans. ${ }^{14}$ Five patients were assumed to be alive because their names did not appear in the BIRLS file. Exact cause of death during the follow-up period could be ascertained for $81 \%$ of the patients. Fifty-two percent of these patients died of a known cardiac cause, mostly congestive heart failure.

\section{Data and Statistical Analyses}

Research assistants prospectively collected a standard set of data on each patient undergoing intraoperative myocardial $\mathrm{pH}$ monitoring. Information on diabetes was obtained retrospectively. Analyses were performed only on complete sets of data. Missing values were not imputed. The characteristics of the patients who survived were compared with those of the patients who died during the follow-up period with the $t$ test for continuous variables and chi-square test for categoric variables. Continuous preoperative and intraoperative variables were then subjected to a bivariate automatic interaction detection analysis, ${ }^{15,16}$ wherein the dependent variable, death versus survival during the follow-up period, was dichotomous. The automatic interaction detection analysis identified the optimal cut point of the preoperative or intraoperative variable that had the greatest reduction in the error variance of the dependent variable; that is, the threshold value that would most significantly affect long-term mortality. Preoperative and intraoperative variables were then entered into a multivariate Cox proportional hazards regression analysis with long-term survival time as the dependent variable. Dichotomized $\mathrm{pH}$ variables identified by automatic interaction detection analysis to be significant at $P<.10$ were categorically entered into the Cox regression analysis to determine whether their respective threshold values were independent predictors of long-term survival after adjustment for other confounding variables. Because of the interdependence of the three $\mathrm{pH}_{37 \mathrm{C}}$ variables analyzed for this study, they were each entered separately into the Cox regression model to determine whether each was independently predictive of long-term survival. 
TABLE 1. Comparison between living and dead patients

\begin{tabular}{|c|c|c|c|c|c|c|c|}
\hline & \multicolumn{3}{|c|}{ Living (n = 287) } & \multicolumn{3}{|c|}{ Dead $(n=240)$} & \multirow[b]{3}{*}{$P$ value } \\
\hline & \multicolumn{3}{|c|}{ Mean \pm SD } & \multicolumn{3}{|c|}{ Mean \pm SD } & \\
\hline & n & or $\%$ & Range & n & or $\%$ & Range & \\
\hline Age at operation (y) & 287 & $62.2 \pm 10.0$ & $24-84$ & 239 & $63.6 \pm 8.5$ & $40-90$ & .085 \\
\hline Sex & & & & & & & .463 \\
\hline Female & 5 & $1.7 \%$ & & 2 & $1.2 \%$ & & \\
\hline Male & 282 & $98.3 \%$ & & 237 & $98.2 \%$ & & \\
\hline \multicolumn{8}{|l|}{ Presence of diabetes mellitus } \\
\hline Yes & 56 & $24.4 \%$ & & 49 & $30.4 \%$ & & .203 \\
\hline No & 174 & $75.6 \%$ & & 112 & $69.6 \%$ & & \\
\hline $\begin{array}{c}\text { Preoperative left ventricular } \\
\text { ejection fraction }(\%)\end{array}$ & 230 & $46.3 \pm 14.7$ & $10-88$ & 183 & $44.8 \pm 15.3$ & $10-82$ & .299 \\
\hline Operation type & & & & & & & .124 \\
\hline CABG & 163 & $56.8 \%$ & & 116 & $48.3 \%$ & & \\
\hline $\begin{array}{l}\text { CABG plus valve replacement } \\
\text { or repair }\end{array}$ & 67 & $23.3 \%$ & & 72 & $30.0 \%$ & & \\
\hline Valve replacement or repair & 57 & $19.9 \%$ & & 52 & $21.7 \%$ & & \\
\hline Duration of $A C$ (min) & 286 & $79.1 \pm 35.3$ & $20-231$ & 236 & $88.2 \pm 44.7$ & $20-306$ & .01 \\
\hline Duration of CPB (min) & 284 & $148.3 \pm 47.1$ & $63-231$ & 236 & $176.9 \pm 72.0$ & $56-467$ & $<.001$ \\
\hline Year of operation within 1982-1990 & 95 & $33.1 \%$ & & 159 & $67.1 \%$ & & \\
\hline Year of operation within 1991-1997 & 185 & $66.9 \%$ & & 77 & $32.9 \%$ & & \\
\hline \multicolumn{8}{|l|}{ Myocardial tissue $\mathrm{pH}_{37 \mathrm{c}}{ }^{*}$} \\
\hline Before AC & 183 & $6.65 \pm 0.27$ & $5.90-7.44$ & 171 & $6.59 \pm 0.29$ & $5.90-7.50$ & .052 \\
\hline Mean during $A C$ & 244 & $6.55 \pm 0.30$ & $5.62-7.36$ & 210 & $6.49 \pm 0.33$ & $5.61-7.32$ & .034 \\
\hline At discontinuation of CPB & 234 & $7.03 \pm 0.30$ & $5.70-7.82$ & 203 & $6.97 \pm 0.37$ & $5.30-7.53$ & .002 \\
\hline
\end{tabular}

$C A B G$, Coronary artery bypass grafting.

* Lower of anterior or posterior $\mathrm{pH}_{37 \mathrm{C}}$ value.

All statistical analyses were performed with SAS Institute statistical software version 8.2 (SAS Institute, Inc, Cary, NC). Continuous variables are expressed as mean $\pm \mathrm{SD}$, and categoric variables are expressed as percentages.

\section{Results}

Thirty-nine $(7.3 \%)$ of 535 consecutive patients who underwent cardiac surgery with myocardial $\mathrm{pH}$ monitoring between June 1982 and August 1997 died within 30 postoperative days. Four hundred ninety-six patients survived beyond the first 30 postoperative days and were followed up to August 31, 2000 (an average follow up of $10.2 \pm 4.9$ years). The average survival after the cardiac operation was $7.6 \pm 4.6$ years; the median survival was 6.7 years. The characteristics of the patients who survived versus those who died during the period of follow-up are shown in Table 1. Differences were noted in duration of $\mathrm{AC}$, duration of $\mathrm{CPB}$, and the three myocardial $\mathrm{pH}_{37 \mathrm{C}}$ measurements.

Table 2 shows the results of automatic interaction detection analysis applied to the continuous preoperative and intraoperative variables listed in Table 1. This bivariate analytic algorithm identifies the breakpoint at which a variable's effect on long-term mortality is most significant. Long-term mortality was most significantly affected when patient age was greater than 52 years, duration of $\mathrm{AC}$ was greater than 135 minutes, and the duration of CPB exceeded 212 minutes. A threshold of preoperative left ventricular ejection fraction of $21 \%$ or less was identified, but with borderline significance $(P=.10)$, reflecting the limited sample size of this variable. Ejection fraction was confirmed to be a significant predictor of long-term survival when it was entered into the multivariate model. The degrees of myocardial acidosis most significantly affecting long-term survival were $\mathrm{pH}_{37 \mathrm{C}}$ less than 6.63 before $\mathrm{AC}$, mean $\mathrm{pH}_{37 \mathrm{C}}$ less than 6.35 during $\mathrm{AC}$, and $\mathrm{pH}_{37 \mathrm{C}}$ less than 6.73 at discontinuation of CPB.

Table 3 shows the results of multivariate Cox proportional hazard analysis where the dependent variable was the postoperative survival time in years. Three models are presented, because each $\mathrm{pH}_{37 \mathrm{C}}$ variable was entered into a separate model, and there was no violation of the proportional hazards assumption in any of the models. Acidosis in either the anterior or posterior left ventricular wall during each of the time points investigated in this study was independently predictive of decreased long-term postoperative survival. The risk ratio was highest for the mean $\mathrm{pH}_{37 \mathrm{C}}$ during AC (relative risk 2.15, $P=.001$ ), indicating that a mean $\mathrm{pH}_{37 \mathrm{C}}$ less than 6.34 during this period in either the anterior or the posterior left ventricular wall was indepen- 
TABLE 2. Optimum threshold points of continuous variables with automatic interaction detection algorithm, with mortality during period of follow-up as dependent variable

\begin{tabular}{|c|c|c|c|c|}
\hline & $\begin{array}{c}\text { Threshold } \\
\text { point }\end{array}$ & $P$ value & $\begin{array}{l}\text { Odds } \\
\text { ratio }\end{array}$ & $\begin{array}{c}95 \% \text { Confidence } \\
\text { interval }\end{array}$ \\
\hline Age $(y)$ & 52 & .010 & 2.03 & $1.19-3.47$ \\
\hline Preoperative left ventricular ejection fraction (\%) & 21 & .102 & 2.12 & $0.86-5.24$ \\
\hline Duration of $A C$ (min) & 135 & $<.001$ & 3.14 & $1.70-5.18$ \\
\hline Duration of CPB (min) & 212 & $<.001$ & 3.16 & $1.92-5.18$ \\
\hline \multicolumn{5}{|l|}{ Myocardial tissue $\mathrm{pH}_{37 \mathrm{c}}{ }^{*}$} \\
\hline Before AC & 6.63 & .008 & 1.77 & $1.16-2.70$ \\
\hline Mean during $A C$ & 6.34 & .004 & 1.86 & $1.22-2.84$ \\
\hline At discontinuation of CPB & 6.73 & $<.001$ & 2.51 & $1.50-4.18$ \\
\hline
\end{tabular}

*Lower of anterior or posterior $\mathrm{pH}_{37 \mathrm{C}}$ value.

dently associated with more than twice the risk of mortality during the follow-up period than was $\mathrm{pH}_{37 \mathrm{C}}$ of at least 6.34 .

In addition to the myocardial $\mathrm{pH}_{37 \mathrm{C}}$ variables, the three models presented in Table 3 were consistent in identifying the following variables as independent predictors of postoperative survival: patient age, presence of diabetes mellitus, preoperative left ventricular ejection fraction, and total duration of CPB. The year of surgery, type of operation, and identity of the surgeon were not determinant of long-term survival. The duration of $\mathrm{AC}$ and whether a sanguineous or a crystalloid cardioplegic solution was used during this period also did not have a significant independent influence on long-term survival. All three models used the same set of 11 risk factors.

Linear regression analysis showed that within each ventricular segment $\mathrm{pH}_{37 \mathrm{C}}$ values at each of the three time points were correlated with each other, with $r$ ranging between 0.4 and 0.5 and $P<.001$.

Risk-adjusted proportional hazards survival curves were constructed to illustrate the effect of the three myocardial $\mathrm{pH}_{37 \mathrm{C}}$ variables that were found to be independent predictors of survival (Figure 2). For each of these variables, the patients were divided into two groups according to the breakpoint $\mathrm{pH}$ determined by the automatic interaction detection analysis (Table 2), after adjustment for all the confounding variables shown to be significant in Table 3 . The survival curves between the two patient groups in each of the three $\mathrm{pH}_{37 \mathrm{C}}$ variables were significantly different. Median survival in the group with a $\mathrm{pH}_{37 \mathrm{C}}$ of at least 6.63 before $\mathrm{AC}$ was 15.2 years, in contrast to 11 years in the group with a $\mathrm{pH}_{37 \mathrm{C}}$ lower than 6.63. Significant regional acidosis before $\mathrm{AC}$ was thus independently associated with a $27.6 \%$ reduction in median survival $(P=.021)$. Median survival in the group with a mean $\mathrm{pH}_{37 \mathrm{C}}$ of at least 6.35 during $\mathrm{AC}$ was 14.4 years, in contrast to 9.5 years in the group with a $\mathrm{pH}_{37 \mathrm{C}}$ less than 6.63. Significant regional acidosis during $\mathrm{AC}$ was thus independently associated with a $34.0 \%$ reduction in median survival $(P=.001)$. Median survival in the group with a $\mathrm{pH}_{37 \mathrm{C}}$ of at least 6.73 at discon- tinuation of CPB was 14.1 years, in contrast to 10.5 years in the group with a $\mathrm{pH}_{37 \mathrm{C}}$ less than 6.74. Significant regional acidosis at the end of CPB was thus independently associated with a $25.5 \%$ reduction in median survival $(P=.023)$.

Figure 3 shows similarly risk-adjusted survival curves of three groups of patients separated according to the relationship between myocardial $\mathrm{pH}_{37 \mathrm{C}}$ before $\mathrm{AC}$ and mean myocardial $\mathrm{pH}_{37 \mathrm{C}}$ during AC. Patients in whom both values were above their respective thresholds $(\mathrm{n}=$ 77) had the best survival (median survival 15.1 years), whereas patients in whom both values were below their respective thresholds $(n=49)$ had the worst survival (median survival 7.9 years). Patients in whom $\mathrm{pH}_{37 \mathrm{C}}$ was below the threshold before $\mathrm{AC}$ and above the threshold during AC $(n=63)$ had a median survival of 13.2 years. Thus, patients who exhibited significant regional acidosis before and during $\mathrm{AC}$ had a $47.7 \%$ reduction in median survival relative to patients who exhibited higher than threshold $\mathrm{pH}_{37 \mathrm{C}}$ during both periods, and raising the $\mathrm{pH}$ from lower than threshold before $\mathrm{AC}$ to higher than threshold during $\mathrm{AC}$ increased the median survival of patients by $40.2 \%$.

\section{Discussion}

Myocardial tissue acidosis, as measured with the technology used in this study and with mass spectrometry, has been shown to be quantitative of regional myocardial ischemia. ${ }^{17-20}$ As such, this study demonstrates that regional myocardial acidosis/ischemia, encountered intraoperatively either (1) before the application of the AC, (2) during AC, and (3) at discontinuation of $\mathrm{CPB}$, is independently determinant of decreased long-term patient survival after cardiac surgery. The study identified specific threshold levels of acidosis that relate to postoperative outcomes to facilitate the surgeon's intraoperative decision making when he or she uses $\mathrm{pH}$-guided myocardial management clinically. These thresholds were as follows: $\mathrm{pH}_{37 \mathrm{C}}$ less than 6.63 before $\mathrm{AC}$, mean $\mathrm{pH}_{37 \mathrm{C}}$ less than 6.35 during $\mathrm{AC}$, and 
TABLE 3. Predictive models based on Cox proportional hazards regression analysis with long-term survival as dependent variable

\begin{tabular}{|c|c|c|c|}
\hline Variable & Model 1 & Model 2 & Model 3 \\
\hline \multicolumn{4}{|l|}{ Age at time of surgery } \\
\hline Risk ratio $(\mathrm{Cl})$ & $1.03(1.00-1.06)$ & $1.05(1.02-1.08)$ & $1.04(1.02-1.07)$ \\
\hline$P$ value & .06 & .001 & .002 \\
\hline \multicolumn{4}{|l|}{ Presence of diabetes mellitus } \\
\hline Risk ratio (CI) & $1.85(1.13-3.03)$ & $1.93(1.24-3.04)$ & $1.95(1.23-3.09)$ \\
\hline$P$ value & .015 & .004 & .004 \\
\hline \multicolumn{4}{|l|}{ Preoperative ejection fraction } \\
\hline Risk ratio (CI) & $0.97(0.95-0.98)$ & $0.97(0.96-0.99)$ & $0.97(0.95-0.98)$ \\
\hline$P$ value & $<.001$ & $<.001$ & $<.001$ \\
\hline \multicolumn{4}{|l|}{ Year of surgery (1991-1997) } \\
\hline Risk ratio (reference group) & 1 & 1 & 1 \\
\hline \multicolumn{4}{|l|}{ Year of surgery (1982-1990) } \\
\hline Risk ratio $(\mathrm{Cl})$ & $1.62(0.89-2.92)$ & $1.70(0.96-3.01)$ & $1.32(0.74-2.36)$ \\
\hline$P$ value & .11 & .07 & .35 \\
\hline \multicolumn{4}{|l|}{ Surgery type all other } \\
\hline Risk ratio (reference group) & 1 & 1 & 1 \\
\hline \multicolumn{4}{|c|}{ Surgery type coronary artery bypass grafting } \\
\hline Risk ratio $(\mathrm{Cl})$ & $2.09(0.98-4.47)$ & $1.85(0.94-3.64)$ & $1.36(0.65-2.83)$ \\
\hline$P$ value & .06 & .08 & .42 \\
\hline \multicolumn{4}{|l|}{ Surgeon 1} \\
\hline Risk ratio (reference group) & 1 & 1 & 1 \\
\hline \multicolumn{4}{|l|}{ Surgeon 2} \\
\hline Risk ratio (CI) & $0.92(0.49-1.72)$ & $0.80(0.46-1.38)$ & $0.75(0.43-1.33)$ \\
\hline$P$ value & .8 & .42 & .32 \\
\hline \multicolumn{4}{|l|}{ Surgeon 3} \\
\hline Risk ratio (Cl) & $0.51(0.21-1.23)$ & $0.59(0.28-1.26)$ & $0.67(0.32-1.40)$ \\
\hline$P$ value & .14 & .17 & .291 \\
\hline \multicolumn{4}{|l|}{ Duration of $A C$} \\
\hline Risk ratio $(\mathrm{Cl})$ & $1.01(0.99-1.02)$ & $1.00(0.99-1.02)$ & $1.00(0.99-1.01)$ \\
\hline$P$ value & .37 & .5 & .94 \\
\hline \multicolumn{4}{|l|}{ Cardioplegia type blood } \\
\hline Risk ratio (reference group) & 1 & 1 & \\
\hline \multicolumn{4}{|l|}{ Cardioplegia type crystalloid } \\
\hline Risk ratio (CI) & $1.42(0.69-2.93)$ & $1.29(0.65-2.56)$ & $1.54(0.79-3.02)$ \\
\hline$P$ value & .35 & .46 & .21 \\
\hline \multicolumn{4}{|l|}{ Duration of CPB } \\
\hline Risk ratio (CI) & $1.01(1.00-1.02)$ & $1.01(1.005-1.014)$ & $1.01(1.005-1.01)$ \\
\hline$P$ value & .001 & $<.001$ & $<.001$ \\
\hline \multicolumn{4}{|l|}{$\mathrm{pH}_{37 \mathrm{C}}<6.63^{*}$ before $\mathrm{AC}$} \\
\hline Risk ratio (CI) & $1.79(1.09-2.93)$ & & \\
\hline$P$ value & .021 & & \\
\hline \multicolumn{4}{|l|}{ Mean $\mathrm{pH}_{37 \mathrm{C}}<6.34^{*}$ during $\mathrm{AC}$} \\
\hline Risk ratio $(\mathrm{Cl})$ & & $2.15(1.37-3.37)$ & \\
\hline$P$ value & & .001 & \\
\hline \multicolumn{4}{|l|}{$\mathrm{pH}_{37 \mathrm{C}}<6.73^{*}$ at end of $\mathrm{CPB}^{*}$} \\
\hline Risk ratio $(\mathrm{Cl})$ & & & $1.70(1.08-2.69)$ \\
\hline$P$ value & & & .023 \\
\hline
\end{tabular}

$\mathrm{Cl}, 95 \%$ Confidence interval.

* Lower of anterior or posterior $\mathrm{pH}_{37 \mathrm{C}}$, each time point entered separately into model. 


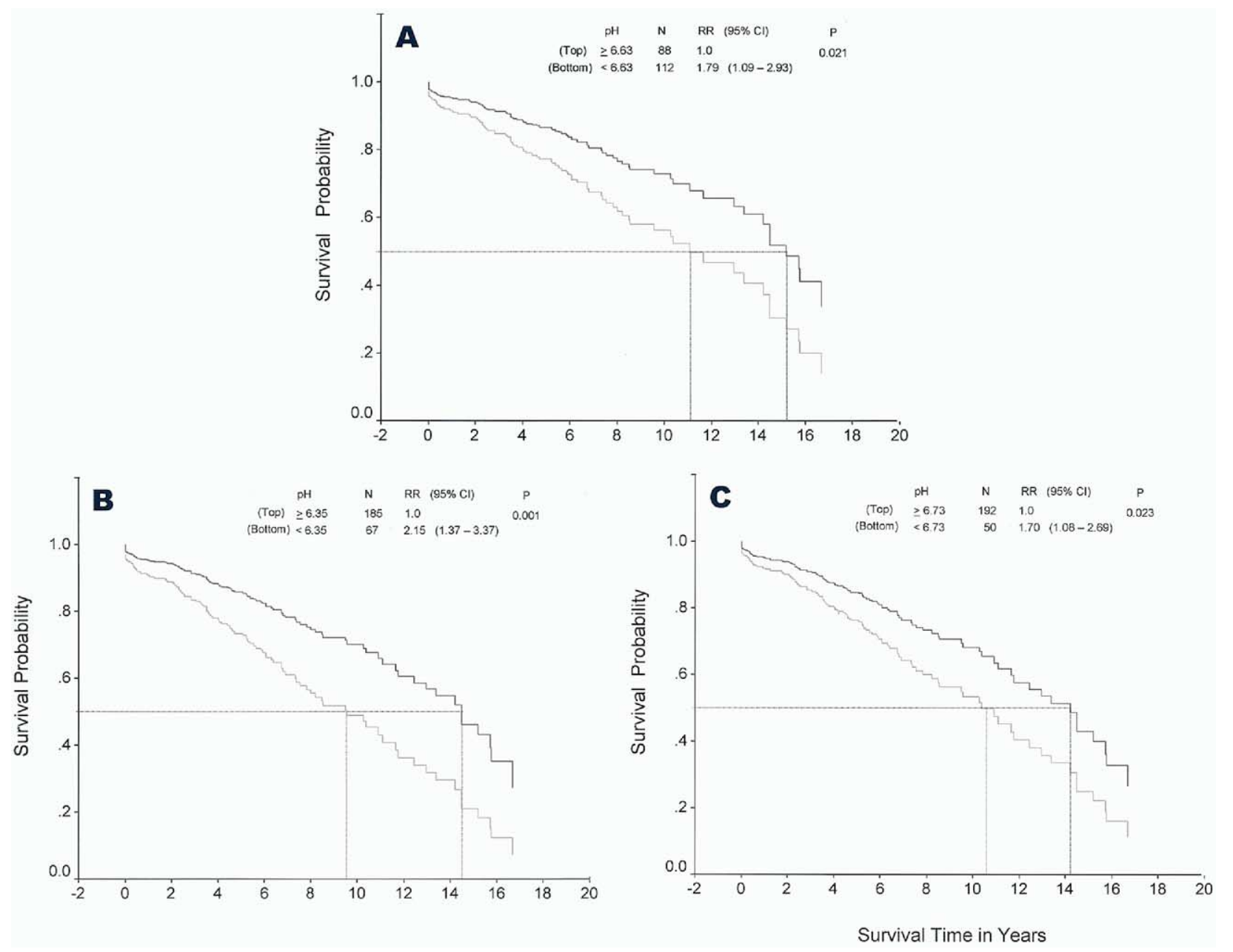

Figure 2. Survival probability curves (adjusted for other variables in the Cox proportional hazards regression model: age, preoperative ejection fraction, diabetes, year of surgery, operation type, surgeon, cardioplegia type, duration of $\mathrm{AC}$, and duration of $\mathrm{CPB}$ ) of patients in whom $\mathrm{pH}_{37 \mathrm{c}}$ was above (top line) or below (bottom line) threshold determined by automatic interaction detection analysis to affect most significantly long-term mortality. Risk ratio (RR) and $95 \%$ confidence interval (CI) of group with lower $\mathrm{pH}_{37 \mathrm{C}}$ versus group with higher $\mathrm{pH}_{37 \mathrm{C}}$ are shown on figure. Vertical line at $\mathbf{5 0} \%$ survival probability defines median survival for each patient group. A, Survivals of patients in whom lower of anterior or posterior wall $\mathrm{pH}_{37 \mathrm{c}}$ before $\mathrm{AC}$ was above (top) or below (bottom) 6.63. B, Survivals of patients in whom lower of anterior or posterior wall integrated mean $\mathrm{pH}_{37 \mathrm{C}}$ during $\mathrm{AC}$ was above (top) or below (bottom) 6.34 . C, Survivals of patients in whom lower of anterior or posterior wall $\mathrm{pH}_{37 \mathrm{C}}$ at discontinuation of CPB was above (top) or below (bottom) 6.34 .

$\mathrm{pH}_{37 \mathrm{C}}$ less than 6.73 at discontinuation of CPB. Considering that normal myocardial $\mathrm{pH}_{37}$ is 7.2 , these thresholds represent varying levels of myocardial acidosis. Found to be significant by automatic interaction detection analysis, which is a univariate analysis, these thresholds were entered as dichotomous variables into the multivariate Cox regression analysis, which confirmed the independent predictive relationship between each of these variables and long-term survival. In addition to intraoperative myocardial acidosis/ ischemia, independent determinants of decreased survival after cardiac surgery were increased patient age, the pres- ence of diabetes mellitus, decreased preoperative left ventricular ejection fraction, and prolonged duration of CPB. Whereas the latter variables have previously been shown to be determinants, either directly ${ }^{21,22}$ or indirectly, ${ }^{23}$ of longterm survival after cardiac surgery, this study is the first to establish such a determinant role for intraoperative regional acidosis. This study, however, does not account for the impact of other, unmeasured variables on the long-term survival of patients undergoing cardiac surgery.

Myocardial acidosis before $A C$ is indicative of myocardial ischemia that can be due to the severity of the patient's 


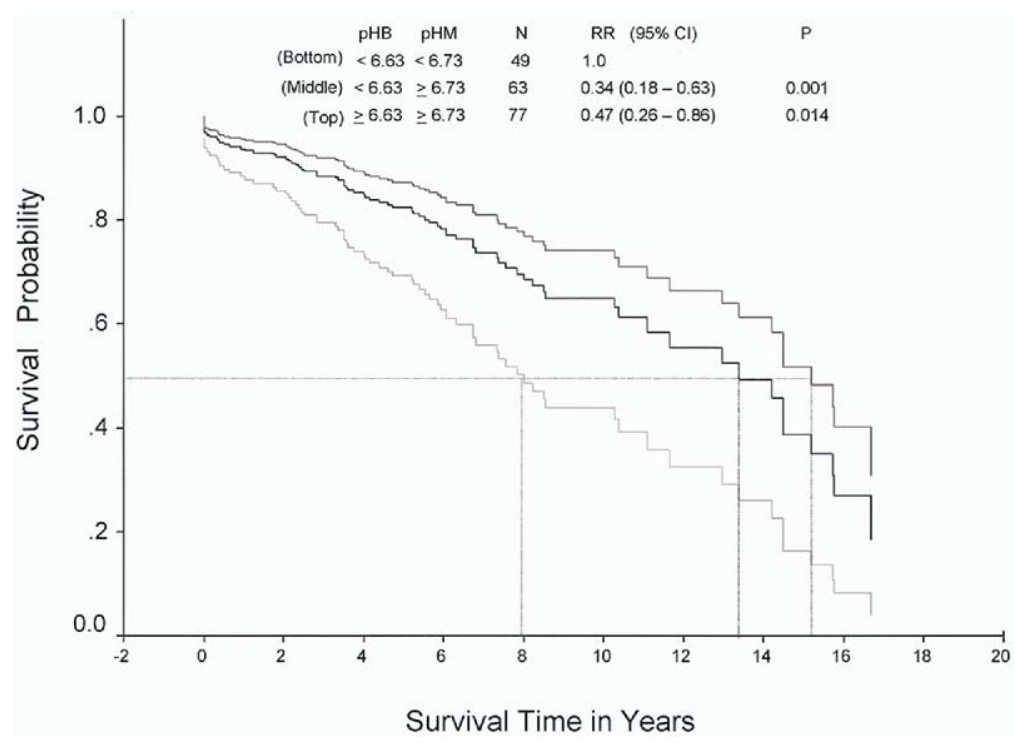

Figure 3. Survival probability curves (adjusted for other variables in Cox proportional hazards regression model: age, preoperative ejection fraction, diabetes, year of surgery, operation type, surgeon, cardioplegia type, duration of $\mathrm{AC}$, and duration of $\mathrm{CPB}$ ) for three groups of patients. First group (top tracing) had lower of anterior or posterior $\mathrm{pH}_{37 \mathrm{C}}$ before $\mathrm{AC}$ and at end of CPB above thresholds respectively determined to affect long-term survival. Second group (bottom tracing) had both values below such thresholds. Third group (middle tracing) had lower of anterior or posterior $\mathrm{pH}_{37 \mathrm{C}}$ before $\mathrm{AC}$ below threshold determined to affect long-term survival, and that at end of CPB above threshold. Risk ratio (RR) and $95 \%$ confidence interval (Cl) of second and third groups versus first group are shown on figure. Vertical line at $\mathbf{5 0} \%$ survival probability defines median survival for each patient group.

underlying coronary artery disease or to the conditions of perfusion, such as low systemic perfusion pressure in the presence of coronary artery obstruction or left ventricular hypertrophy. ${ }^{24}$

Regional myocardial acidosis during $A C$ has been shown to relate to adverse short-term clinical outcomes. ${ }^{2,7,11}$ In our models, regional myocardial acidosis during this period had the highest risk ratio and was the most important myocardial $\mathrm{pH}$ variable in affecting long-term survival; it was also more important than the other 4 non-pH variables in the model. Previous studies have claimed that acidosis is protective to the myocardium during ischemia. ${ }^{25,26}$ However, the range of acidosis shown to be protective in those studies $(\mathrm{pH}$ 6.8-7.0) was much less severe than the acidosis found to be adverse to long-term survival in this study $\left(\mathrm{pH}_{37 \mathrm{C}}<6.35\right)$. Intraoperative myocardial protection techniques in cardiac surgery have been directed toward the prevention of myocardial ischemia during $\mathrm{AC}$, but there have not been clinical tools with which the efficacy of myocardial protection could be assessed on-line during this period. Regional acidosis during this period is in good part the result of inadequate delivery of the cardioplegic solution, which distributes in the myocardial wall in a heterogeneous and unpredictable manner. ${ }^{1,12}$ We have demonstrated that the delivery of the cardioplegic solution to a specific segment of the left ventricular wall can be improved, and myocardial acidosis in that segment can be reduced or totally ameliorated by a variety of intraoperative maneuvers guided by myocardial $\mathrm{pH}$ monitoring. ${ }^{1,3,9}$ The findings of this study confirm the importance of preventing acidosis during $\mathrm{AC}$ and underscore the potential of intraoperative $\mathrm{pH}$-guided myocardial management in improving postoperative long-term patient survival.

Regional myocardial acidosis at discontinuation of $C P B$ is a reflection of either inadequate intraoperative myocardial protection or inadequate myocardial revascularization. Both of these factors account for most adverse events after cardiac surgery. ${ }^{27}$ Inadequate intraoperative myocardial protection during AC precipitates a "no reflow" injury during reperfusion ${ }^{28}$ and prevents adequate washout of the hydrogen ion, resulting in persistent acidosis throughout the reflow period. Inadequate revascularization also limits the washout of the hydrogen ion and results in persistent ischemia. Successful restoration of blood flow to an ischemic segment that has not been subject to reperfusion injury should effect a complete washout of excess hydrogen ion and eliminate tissue acidosis before discontinuation of CPB. ${ }^{13,17}$

The relationship between acidosis before and during AC underscores the importance of reversing regional acidosis during AC. As demonstrated in Figure 3, patients who had their $\mathrm{pH}_{37 \mathrm{C}}$ raised from below threshold before to above 
threshold during AC had nearly twice the survival of patients in whom myocardial protective techniques failed to raise $\mathrm{pH}_{37 \mathrm{C}}$ from below threshold before to above threshold during AC. The curves in Figure 3 show the effect of acidosis on survival, corrected for the other confounding variables identified in the study, including the year rang of the operation, which approached statistical significance as a separate independent predictive factor in model 2 (Table 3).

Recent experiments performed in animals and human beings have shed light on a possible etiology for the adverse effect of intraoperative myocardial acidosis on long-term patient survival. Cell culture studies have shown acidosis to be a primary trigger for apoptosis. ${ }^{29}$ We recently demonstrated a direct relationship between acidosis and apoptosis in atrial muscle tissue obtained from patients undergoing cardiac surgery and in ventricular muscle biopsy specimens obtained from pigs undergoing $\mathrm{CPB} .{ }^{30}$ Pending the results of ongoing studies that are attempting to elucidate the relationship between apoptosis and congestive heart failure, it may soon be possible to hypothesize that intraoperative myocardial acidosis, through its acceleratory effect on apoptosis, may contribute to postoperative congestive heart failure, which is one of the major causes of late mortality after cardiac surgery.

In summary, this is the first documentation of the adverse impact of intraoperative myocardial acidosis, and thus myocardial ischemia, on long-term patient survival. The main limitations of this study, however, are its observational nature, the fact that it has emanated from a single institution, and that any validation of the findings will require several years, hopefully through multicenter studies that need to be conducted when this technology becomes available for routine clinical use.

We acknowledge with gratitude the help provided by Dr Joseph Loscalzo and Dr Mark Pfeffer, who reviewed the data and early versions of this article and provided valuable suggestions and advice. The administrative help of Mrs Lynne Santangelo is also acknowledged with gratitude.

\section{References}

1. Khuri SF. pH-guided myocardial management: evolution and clinical application. 1st ed. Ann Arbor (MI): Terumo Cardiovascular Systems Corporation; 2003.

2. Khuri SF, Josa M, Marston W, Braunwald NS, Smith B, Tow D, et al. First report of intramyocardial $\mathrm{pH}$ in man. II. Assessment of adequacy of myocardial preservation. J Thorac Cardiovasc Surg. 1983;86:66778 .

3. Khabbaz KR, Zankoul F, Warner KG. Intraoperative metabolic monitoring of the heart: II. Online measurement of myocardial tissue $\mathrm{pH}$ Ann Thorac Surg. 2001;72:S2227-34.

4. Khuri SF, Marston WA, Josa M, Braunwald NS, Cavanaugh AC, Hunt $\mathrm{H}$, et al. Observations on 100 patients with continuous intraoperative monitoring of intramyocardial $\mathrm{pH}$. The adverse effects of ventricular fibrillation and reperfusion. $J$ Thorac Cardiovasc Surg. 1985;89:17082.

5. Khuri SF, Warner KG, Marston W, Josa M, Sharma GV, Tow D, et al. Intraoperative assessment of the physiologic significance of coronary stenosis in humans. $J$ Thorac Cardiovasc Surg. 1986;92:79-87.

6. Warner KG, Khuri SF, Kloner RA, Josa M, Dalecki-Chipperfield KM, Butler MD, et al. Structural and metabolic correlates of cell injury in the hypertrophied myocardium during valve replacement. $J$ Thorac Cardiovasc Surg. 1987;93:741-54.

7. Khuri SF, Warner KG, Josa M, Butler M, Hayes A, Hanson R, et al. The superiority of continuous cold blood cardioplegia in the metabolic protection of the hypertrophied human heart. $J$ Thorac Cardiovasc Surg. 1988;95:442-54.

8. Khuri SF, Axford TC, Garcia JP, Khabbaz KR, Dearani JA, Khait I, et al. Metabolic correlates of myocardial stunning and the effect of cardiopulmonary bypass. J Cardiac Surg. 1993;8(Suppl):262-70.

9. Khuri SF. Invited discussion on Khabbaz et al. Intraoperative metabolic monitoring of the heart: II. Online measurement of myocardial tissue pH. Ann Thorac Surg. 2001;72:S2233-4.

10. Dearani JA, Axford TC, Patel MA, Healey NA, Lavin PT, Khuri SF. The role of myocardial temperature in monitoring the adequacy of myocardial protection during cardiac surgery. Ann Thorac Surg. 2001; 72:S2235-43.

11. Biswas KS, Hossain M, Healey N, Birjiniuk V, Crittenden MD, Khuri SF. Intraoperative myocardial acidosis predicts adverse outcomes following cardiac surgery. Circulation. 1999;100(18 Suppl): I596.

12. Khuri SF, Healey NA, Zolkewitz M, Khait I, Birjiniuk V, Doursounian M. Determinants of myocardial tissue acidosis during prolonged aortic clamping. Circulation. 1996;94(Suppl):I372.

13. Wolfe JA. The coronary artery bypass conduit: II. Assessment of the quality of the distal anastomosis. Ann Thorac Surg, 2001;72:S2253-9.

14. Page WF, Mahan CM, Kang HK. Vital status ascertainment through the files of the Department of Veteran Affairs and the Social Security Administration. Ann Epidemiol. 1996;6:102-9.

15. Morgan JA, Sonquist JA. Problems in the analysis of survey data and a proposal. J Am Stat Assoc. 1963;58:415-34.

16. Sonquist JA, Morgan JA. The detection of interaction effects: a report on a computer program for the selection of optimal combinations of explanatory variables. Ann Arbor (MI): Institute for Social Research, University of Michigan; 1964.

17. Khuri SF, Kloner RA, Karaffa SA, Marston W, Taylor AD, Lai NC, et al. The significance of the late fall in myocardial $\mathrm{pCO}_{2}$ and its relationship to myocardial $\mathrm{pH}$ after regional occlusion in the dog. Circ Res. 1985;56:537-47.

18. Khuri SF, Flaherty JT, O'Riordan JB, Pitt B, Brawley RK, Donahoo JS, et al. Changes in intramyocardial ST segment voltage and gas tensions with regional myocardial ischemia in the dog. Circ Res. 1975;37:455-63.

19. Khuri SF, Kloner RA, Hillis LD, Tow DE, Barsamian EM, Maroko $\mathrm{PR}$, et al. Intramural $\mathrm{pCO}_{2}$ : a reliable index of the severity of myocardial ischemic injury. Am J Physiol. 1979;237:H253-9.

20. Axford TC, Dearani JA, Khait I, Park WM, Patel MA, Doursounian M, et al. Electrode-derived myocardial $\mathrm{pH}$ measurements reflect intracellular myocardial metabolism assessed by phosphorus 31-nuclear magnetic resonance spectroscopy during normothermic ischemia. J Thorac Cardiovasc Surg. 1992;103:902-7.

21. Peterson ED, Cowper PA, Jollis JG, Bebchuk JD, DeLong ER, Muhlbaier LH, et al. Outcomes of coronary artery bypass graft surgery in 24,461 patients aged 80 years or older. Circulation. 1995;92(9 Suppl):II $85-91$.

22. Turina J, Milincic J, Seifert B, Turina M. Valve replacement in chronic aortic regurgitation. True predictors of survival after extended followup. Circulation. 1998;98(19 Suppl):II100-7.

23. Milano CA, Kesler K, Archibald N, Sexton DJ, Jones RH. Mediastinitis after coronary artery bypass graft surgery. Circulation. 1995;92: 2245-51.

24. Khuri SF, Brawley RK, O'Riordan JB, Donahoo JS, Pitt B, Gott VL. The effect of cardiopulmonary bypass perfusion pressure on myocardial gas tensions in the presence of coronary stenosis. Ann Thorac Surg. 1975;20:661-70. 
25. Koop A, Piper HM. Protection of energy status of hypoxic cardiomyocytes by mild acidosis. J Mol Cell Cardiol. 1992;24:55-65.

26. Naylor WG, Ferrari R, Poole-Wilson PA, Yepez CE. A protective effect of a mild acidosis on hypoxic heart muscle. J Mol Cell Cardiol. 1973;11:1053-71.

27. O'Connor GT, Birkmeyer JD, Dacey LJ, Quinton HB, Marrin CA, Birkmeyer NJ, et al. Results of a regional study of modes of death associated with coronary artery bypass grafting. Northern New England Cardiovascular Disease Study Group. Ann Thorac Surg. 1998;66:1323-8.
28. Reffelman T, Kloner RA. The 'no-reflow' phenomenon; basic science and clinical correlates. Heart. 2002;87:162-8.

29. Webster KA, Discher DJ, Kaiser S, Hernandez O, Sato B, Bishopric $\mathrm{NH}$. Hypoxia-activated apoptosis of cardiac myocytes requires reoxygenation or a $\mathrm{pH}$ shift and is independent of p53. J Clin Invest. 1999;104:239-52.

30. Thatte HS, Rhee JH, Zagarins S, Treanor PR, Birjiniuk V, Crittenden $\mathrm{MD}$, et al. Acidosis-induced apoptosis in the human and porcine heart. Ann Thorac Surg. 2004;7:1376-83.

\section{Authoritative}

The Journal of Thoracic and Cardiovascular Surgery is the most frequently cited thoracic/cardiovascular surgery journal in the Science Citation Index. An article in JTCVS is cited on average almost twice as often as those in the closest cardiothoracic journal. 